\title{
LEARNING EMBRYOLOGY: FUN OR FEAR? STUDENTS' PERSPECTIVE
}

\section{Gyata Mehta *1, Varsha Mokhasi ${ }^{2}$, Swapnali Shamkuwar ${ }^{3}$.}

${ }^{{ }^{*} 1}$ Associate professor, Department of Anatomy, Vydehi institute of Medical Sciences \& Research Centre, \#82 EPIP area, Whitefield Bangalore, Karnataka, India.

2 Professor \& HOD, Department of Anatomy, Vydehi institute of Medical Sciences \& Research Centre, \#82 EPIP area, Whitefield Bangalore, Karnataka, India.

${ }^{3}$ Associate professor, Department of Anatomy, Akash Institute of Medical Sciences\& Research Centre, Near Kempegowda International Airport, Devanhalli Bangalore, Karnataka, India.

\section{ABSTRACT}

Background: Embryology forms an important part of Anatomy in medical curriculum. As a subject it is difficult for the first year students. The aim of the study was to make the subject simple, to inculcate interest and to reach to different types of learners as possible and to assess the effect of various teaching methods on learning.

Methods: First year medical students were taught Embryology using different methods over one academic year by one faculty member. In addition to black board and power point as the main methods of teaching, supplementary methods like videos, props, models, handouts \& quiz were also used. These were compared on different parameters of teaching-learning process like conceptual understanding, recollection \& long term memory, reproducibility \& writing in exam, structure and sequence of events, drawing of diagrams, clinical application, overall effectiveness and fun in the process of learning. A comparison of different methods of teaching was done in the form a written feedback questionnaire.

Results: It was observed that 73.9\% students preferred Black board, $21.73 \%$ preferred Power point and $4.34 \%$ opted for videos as the choice of method. The study also revealed that $76.08 \%$ of students preferred a combination of different methods for the embryology lectures, where as $15.21 \%$ preferred only Black Board, $6.52 \%$ preferred only Power Point and $2.17 \%$ of students preferred only Videos as the method for learning Embryology.

Most of the parameters of teaching Embryology were better fulfilled by black board method specially drawing of diagrams ( $82.60 \%$ students). However for clinical application of the subject, power point ( $50.43 \%$ students) was preferred. The students' response revealed that Quiz was a fun loving method of learning (40\%students), whereas (31.3\%students) enjoyed videos on Embryology. The overall effectiveness of Black board was found to be (60.86\%), Power point (18.2\%), Videos (8.69\%), Props (4.34\%), Quiz (3.47\%), Handouts (2.6\%) and Models (1.73\%).

Conclusions: A multi-modal approach was made to facilitate and enhance the learning process of the subject. The study revealed that blackboard was the most valued method for teaching-learning Embryology.

KEY WORDS: Embryology, teaching-learning process, various methods, written feedback.

Corresponding Author: Dr Gyata Mehta, Associate professor, Department of Anatomy, Vydehi institute of Medical Sciences \& Research Centre, \#82 EPIP area, Whitefield Bangalore 560066, Karnataka, India. Mobile no- 9663510832 E-Mail: drgyatamehta@gmail.com

Access this Article online Quick Response code

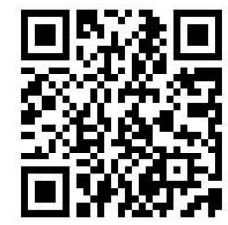

DOI: $10.16965 /$ ijar.2019.319

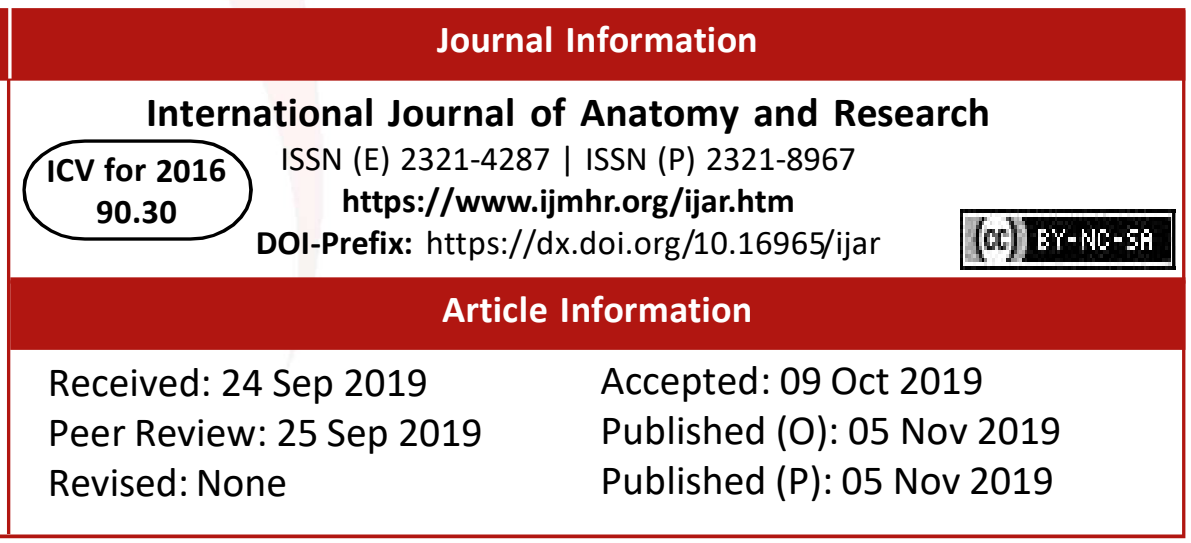

\section{BACKGROUND}

Basic sciences form the key stone of Medical education curriculum. Human Anatomy is the scientific study of the form, position, size and relationship of the structure in the body [1]. Embryology, being part of Anatomy, helps the 
medical students to understand the normal development of human body and forms the basis of various developmental anomalies. In most of the medical colleges, Embryology classes for First year medical students are usually taught by the traditional lecture method. Embryology is not only difficult to imagine and understand by the students, also difficult to comprehend \& reproduce in theory exam. Since weightage to the subject is meagre in theory exam, most students usually study a few topics purely from examination point of view. Very few students have a full grasp of the subject and its application in clinical field. A challenge in Embryology teaching has been the need to demonstrate fast, three dimensional changes occurring both macroscopically \& microscopically [2].

The role of a teacher in the modern concept of medical education is to facilitate the learning process. Technology has proved to be a boon. Teachers can now present the subject to their students with more $3 \mathrm{D}$ images, sequence of images and videos and thus improve the educational value [3].

In an endeavour to encourage student participation in the learning process, multiple techniques were used in the teaching of Embryology. The aim of the study was to make the subject easy \& simple, to inculcate interest and to reach to different types of learners as possible and to assess the effect of various teaching methods on learning.

\section{MATERIALS AND METHODS}

The present study was conducted in the Department of Anatomy, at Vydehi Institute of Medical Sciences and Research Centre, Bangalore, from September2017 to June 2018. The subject population was the batch of First year students comprising of 250 students. All 250 were included in the study. Amongst these, 230 students returned completed feedback questionnaire forms. The remaining proformas were incomplete and hence were not included for analysis.

Embryology was taught using different methods over one academic year by one faculty member. The teaching methods used were; Black Board (BB), Power Point (PPT), Videos, Props, Handouts, Models and Quiz. Total of 26 didactic lectures were taken, out of which, 14 classes were taken by Black board method \& 12 classes by PPT method. In addition to these main methods of teaching, supplementary methods were used to enhance the process of learning. Amongst these 26 classes; videos were shown in 10 classes, props were used in 5 classes, for explanation of Gastro-intestinal system \& Cardiovascular system. Hand-outs were given for 5 classes for General Embryology. Pictures of the models were shown by PPT at the end of each system in the theory lecture and readymade models were shown to the students during practical hours. A quiz was conducted in 2 classes, at the end of General Embryology and at the end of Systemic Embryology.

To compare the effectiveness of different methods of teaching-learning Embryology, used over the year, a feedback was taken from the students in the form of a written questionnaire at the end of the academic session. The parameters used to compare the various methods were; conceptual understanding, recollection \& long term memory, reproducibility \& writing in exam, concept of structure \& sequence of events, drawing of diagrams, clinical application, overall effectiveness and fun in the process of learning.

\section{RESULTS}

A Longitudinal study was done over one academic year. At the end of the academic session, a feedback was taken from the students in the form of a written questionnaire. The data was collected and descriptive statistics was used to present the results.

It was observed that Black board was the preferred choice for overall effectiveness of the learning process and also for parameters like conceptual understanding, recall \& long term memory, reproducibility \& writing in exam and drawing of diagrams. PPT was preferred for the understanding of the clinical application of the topics and videos were preferred for concept of structure and sequence of events. Quiz \& videos were enjoyed by students and made learning a fun process. [Refer Table1]

The students were asked their choice of method for learning Embryology. Black board was the preferred choice by $73.91 \%$ students, PPT by $21.73 \%$ and videos by $4.34 \%$ students. The study also revealed that $76.08 \%$ students preferred 
Gyata Mehta, Varsha Mokhasi, Swapnali Shamkuwar. LEARNING EMBRYOLOGY: FUN OR FEAR? STUDENTS' PERSPECTIVE.

Table 1: Comparison of various methods for teaching Embryology on the basis of different parameters used in the teaching-learning process.

\begin{tabular}{|l|c|c|c|c|c|c|c|}
\hline \multicolumn{1}{|c|}{ Parameters of teaching } & Black board & Power point & Video & Props & Models & Handouts & Quiz \\
\hline Conceptual understanding & $140(60.86 \%)$ & $46(20 \%)$ & $16(6.95 \%)$ & $12(5.21 \%)$ & $10(4.34 \%)$ & $4(1.73 \%)$ & $2(0.86 \%)$ \\
\hline Recall \& long term memory & $110(47.82 \%)$ & $32(13.91 \%)$ & $30(13.04 \%)$ & $12(5.21 \%)$ & $16(6.95 \%)$ & $12(5.21 \%)$ & $18(7.82 \%)$ \\
\hline Reproducibility \& writing in exam & $126(54.78 \%)$ & $56(24.34 \%)$ & $2(0.86 \%)$ & $4(1.73 \%)$ & $8(3.47 \%)$ & $26(11.30 \%)$ & $8(3.47 \%)$ \\
\hline Concept of structure\& sequence of events & $62(26.95 \%)$ & $42(18.2 \%)$ & $88(38.26 \%)$ & $14(6.08 \%)$ & $18(7.82 \%)$ & $4(1.73 \%)$ & $2(0.86 \%)$ \\
\hline Drawing of diagrams & $190(82.60 \%)$ & $20(8.69 \%)$ & $2(0.86 \%)$ & $2(0.86 \%)$ & $6(2.60 \%)$ & $8(3.47 \%)$ & $2(0.86 \%)$ \\
\hline Clinical application & $12(5.21 \%)$ & $116(50.43 \%)$ & $76(33.04 \%)$ & $2(0.86 \%)$ & $14(6.08 \%)$ & $2(0.86 \%)$ & $8(3.47 \%)$ \\
\hline Overall effectiveness & $140(60.86 \%)$ & $42(18.2 \%)$ & $20(8.69 \%)$ & $10(4.34 \%)$ & $4(1.73 \%)$ & $6(2.60 \%)$ & $8(3.47 \%)$ \\
\hline Fun in learning & $26(11.30 \%)$ & $10(4.34 \%)$ & $72(31.3 \%)$ & $16(6.95 \%)$ & $12(5.21 \%)$ & $2(0.86 \%)$ & $92(40 \%)$ \\
\hline
\end{tabular}

a combination of different methods for the Embryology lectures, where as $15.21 \%$ preferred only black board, $6.52 \%$ preferred only PPT and $2.17 \%$ students preferred only videos as the method for learning Embryology.

Fig. 1: Students response on choice of method for teaching Embryology. (BB-Black Board, PPT- Power Point).

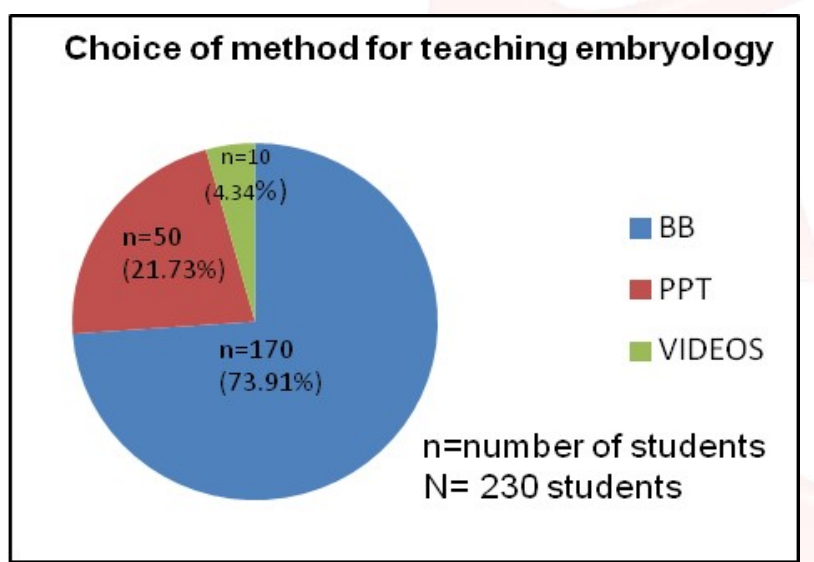

Fig. 2: Students response on preference of combination/ single method for teaching Embryology (BB-Black Board, PPT- Power Point).

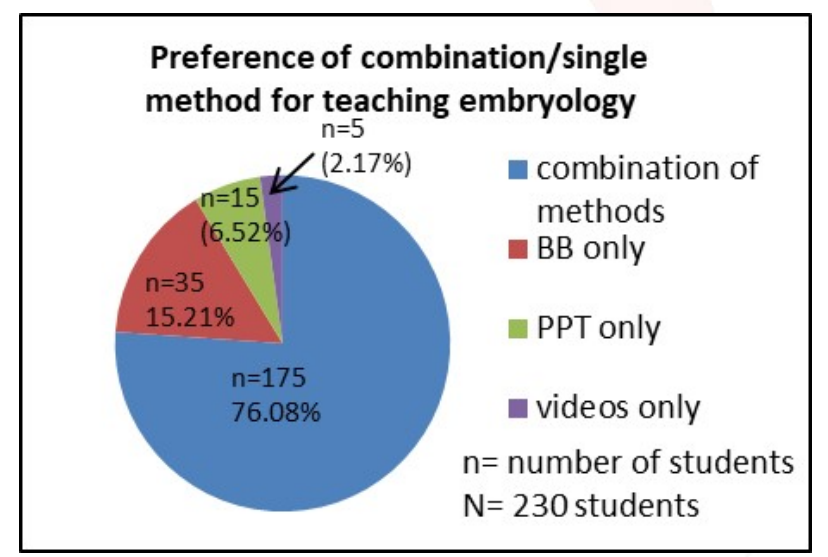

\section{DISCUSSION}

Didactic lecture is the most traditional and common teaching-learning method used to impart education in Embryology. It is a live personal method for motivating, sensitising and stimulating students [4]. However various techniques of imparting the lectures were used to facilitate the learning process. Numerous studies have been done comparing the various methods of teaching Human Anatomy [1, 5, 6, 7]. Embryology being the most difficult part of Anatomy, the present study was focussed only on various methods of teaching Embryology in the First year of medical curriculum. Interestingly a study was done by Karen M Scott [8] with Final year medical students emphasising on teaching Embryology with clinical scenarios in Paediatrics. It showed that $80 \%$ students agreed that understanding of Embryology will help in better clinical management. Optimal timing of learning Embryology was also discussed \& 31\% agreed that Embryology is better taught in first year as a basic science, where as $55 \%$ agreed that it is best to learn Embryology when studying Paediatrics. 90\% students agreed that the use of clinical scenarios as a method used in teaching Embryology would improve their self-directed learning skills. The present study was done with First year MBBS students. On preference of one method of teaching Embryology 170(73.9\%) students opted for Black board method, 50(21.73\%)students preferred PPT and10 (4.34\%) opted for videos. The students opined that in most of the parameters of teaching, like, conceptual understanding, long term memory \& recollection, reproducibility and writing in exam and drawing of diagrams, the Black board method was preferred.

While teaching Embryology, it is expected that a series of events in normal development of embryo are understood in relation to each other. The present study revealed that for clarity in concept of structure and sequence of events, $88(38.26 \%)$ students preferred videos, $62(26.95 \%)$ students preferred Black board 
method and 42(18.2\%) students preferred PPT method of teaching. Embryology being a dynamic subject, a study was done by Rao MP [9] on use of animation as an educational tool in teaching Embryology. An animation module was created, using one of the office tools like power point and emphasised that animations do have an edge over static graphics.

A study was done by Aversi- Ferreira TA [10] of teaching Embryology using model construction by the students in practical classes. The use of this tool has the purpose of facilitating learning since the students can see and touch the models, easily observing the 3 dimensional aspects of the structure [11]. The questionnaire analysis of his study indicated that $95 \%$ students agreed that construction of models themselves, improves the learning and most of the students rated their learning as excellent $(25 \%)$ or good (55\%) and in addition rated their participation during the classes as excellent (50\%) and good (50\%). However in the present study, pictures of the models were shown by PPT at the end of the theory class and models were shown and discussed during the practical hours. The readymade models were used in the study and students were not involved in construction of new models.

With the advent of newer technologies, T Vijay Sagar [12] studied on assisted E- learning computer program as a teaching learning resource on Human Embryology. In his study, $98 \%$ students strongly agreed that the E- learning module was extremely beneficial for learning Embryology. The study group showed a significant improvement in performance as compared to the previous batch which was taught via the traditional method.

To make learning more fun and enhance involvement of students \& interest in the subject, in the present study a Quiz was conducted during the theory period, after General Embryology and again after Systemic Embryology. There was a better involvement of all types of learners and the subject was enjoyed by majority of the students. When compared to black board and PPT, 92(40\%) students felt that Quiz was a fun loving method of learning, whereas 72(31.3\%) enjoyed videos on Embryology. Vasconcelos [13] introduced Crosswords to compliment medical education in a fun way and prepared 150 Crosswords on different stages of embryonic development in three difficulty levels. Students used the crossword as a supplementary activity in the laboratory Embryology classes.

To encourage student participation in the learning process, Nachiket Shankar [4] introduced a Modified Team Based Learning (TBL) method for teaching General Embryology to First year medical graduate students. Their results showed that TBL sessions were better at fulfilling learning objectives, as shown by ( $45 \%$ students), enabled better understanding (79\%students) and ensured greater student participation (94\%students).

A study was done by Mozafar Khazaei et al [14] to determine the effect of student working group establishment on teaching General Embryology course to medical students. The questionnaire at the end of the study showed the positive role of film projection in teaching the materials (95.34\%), significance of presentation of various pictures from different books (88.4\%) and changing students' attitude towards application of Embryology in different diseases (86\%) and repetitions of previous sessions pictures (83.75\%).

In the present study, most of the aspects of teaching Embryology, like conceptual understanding, recall \& long term memory, reproducibility and writing in exams, structure \& sequence of events were better understood by black board method. The feedback showed that black board method of teaching specially helped the students in drawing of diagrams (190students $82.60 \%)$. However for clinical application of the subject, PPT (116 students $50.43 \%$ ) and videos (76students $33 \%$ ) were better methods of choice. The use of free hand drawings to show changes in development over time is a useful strategy to help students understand the sequence of developmental changes [15]. The vast majority of medical students in this study valued black board as the method for teaching learning process in Embryology. The overall effectiveness of Black Board was found to be (60.86\%), PPT (18.2\%), Videos (8.69\%), Props (4.34\%), Quiz (3.47\%), Handouts (2.6\%) and Models (1.73\%). 
Recommendations: Black board teaching should be continued to be used along with other newer and advanced methods.

Limitation of the study: Equal number of classes, for each method of teaching, could not be conducted, for a more accurate comparison.

\section{CONCLUSION}

Embryology teaching is an important part of the medical curriculum. With the advent of increasing research and change in concepts in human Embryology, understanding basics of human development needs to be thoroughly understood in the first year medical career [9]. It is a challenge for the faculty to make the students imagine, understand, comprehend and then reproduce in the theory exam.

A multi-modal approach was made to facilitate and enhance the learning process of the subject. The study revealed that blackboard was the most valued method for teaching-learning Embryology.

\section{ABBREVIATIONS \\ BB- Black Board, \\ PPT- Power Point, \\ TBL-Team Based Learning}

\section{ACKNOWLEDGEMENTS}

We are grateful to Dr Kavita Konapur (Assistant Professor, Community Medicine, Vydehi Institute of Medical Sciences \& Research Centre, Bangalore.

\section{Conflicts of Interests: None}

\section{REFERENCES}

[1]. Vijay Nayak, Utkarsh Shrivastava, Sushil Kumar, Mohan Angadi, Kailash Balkund. Evaluation of various methods of teaching human anatomy. International Journal of Recent Trends in Science and Technology. April2015;14(3):713-715.

[2]. Guimaraes Moraes S,Violin Pereira LA. A multimedia approach for teaching human embryology: development and evaluation of a methodology. Ann.Anat 2010;192:388-95.
[3]. Reenu kumari, Amod Kumar Yadav,Bikramjeet Singh, Manpreet Kaur,Rimpi Gupta. Evaluating anatomy teaching methodology as per the percipience of first year MBBS students - a questionnaire based study. International Journal of Basic and Applied Medical Sciences 2015;5(2):240-247.

[4]. Nachiket Shankar,RoopaR. Evaluation of a modified Team Based Learning method for teaching General Embryology to $1^{\text {st }}$ year medical graduate students. Indian J Med Sci, January2009;63(1):4-12.

[5]. Rashmi Jaiswal, Sameer Sathe, Vivekanand Gajbhiye, Rashmi Sathe. Students Perception on methods of Anatomy teaching and assessment. International Journal of Anatomy and Research 2015;3(2):110308.

[6]. Pushpa Potaliya, Ranabir Pal, Surajit Ghatak. Value and Price of Teaching-Learning Aids in Curricular Health Trainings in India. American Journal of Public Health Research 2015;3(5A):160-173.

[7]. Rokade SA, Bahetee BH. Shall we teach Anatomy with Chalk and Board or Power point Presentation? An analysis of Indian students' Perspective and Performance. Sch J App Med Sci 2013;1(6):837-842.

[8]. Karen M Scott, Antony Robert Charles, Andrew JA Holland. Clinical embryology teaching: is it relevant anymore? ANZ J Surg 2013;83:709-712.

[9]. Rao MP. Animations in medical education: you can do it! Med J DY Patil Univ 2012;5(1):18-22.

[10]. Aversi-Ferreira TA et al. Teaching Embryology Using Models Construction In Practical Classes. Int J Morphol 2012;30(1): 188-195.

[11]. Aziz MA, Mckenzie JC, Wilson JS, Cowie RJ, Ayeni SA,Dunn BK. The human cadaver in the age of biomedical informatics. Anat Rec 2002;269:20-32.

[12]. Vijay Sagar T, Viveka S. Assisted E-Learning Computer Program as a Teaching- Learning Resource on Human Embryology. Indian Journal of Applied Research. 2015;5(12):540-544.

[13]. Vasconcelos ACCG, Soares MC, Silva FRP, Vasconcelos DFP. An alternative methodology for teaching and evaluation in medical education:crosswords. J Morphol.Sci 2015;32(3):165-169.

[14]. Mozafar khazaei, Mohammad Rasool khazaei, Gholam Reza Mohseni, Atefeh Ansarian. The effect of student working group establishment on teaching general embryology course to medical students.Edu R Med S 2012;1(2):12-16.

[15]. Kramer B, Soley J. Medical student perception of problem topics in Anatomy. East Afr.Med J.2002;79:408-14.

How to cite this article:

Gyata Mehta, Varsha Mokhasi, Swapnali Shamkuwar. LEARNING

EMBRYOLOGY: FUN OR FEAR? STUDENTS' PERSPECTIVE. Int J

Anat Res 2019;7(4.2):7127-7131. DOI: 10.16965/ijar.2019.319 